\title{
Influence of Dopants on Mechanical Properties of Steel: A Spin-Polarized Pseudopotential Study
}

\author{
Zavodinsky $\mathbf{V}^{1 *}$ and Kabaldin $\mathbf{Y}^{2}$ \\ 1 Institute for Materials Science of the Russian Academy of Sciences 153 Tikhookeanskaya str., Khabarovsk, 680042, Russia \\ ${ }^{2}$ Nizhny Novgorod State Technical University, 24 Minin str. Nizhny Novgorod, 603013, Russia
}

\begin{abstract}
Density functional theory and pseudopotentials were used to study reaction of the ferrite grains interface (doped with $\mathrm{C}, \mathrm{P}, \mathrm{N}, \mathrm{Ti}, \mathrm{Ti}+\mathrm{N}$ and $\mathrm{Ti}+\mathrm{C}$ ) on deformations. It was shown that impurities could increase or decrease the tensile strength and the elongation limit. The best effect was demonstrated for cases when Ti presents simultaneous with $\mathrm{C}$; the worst case is doping iron with P. As for the shift modulus, effect is not significant.
\end{abstract}

Keywords: $\mathrm{Ab}$ initio simulation; $\alpha$-Fe; Tensile strength; Shift modulus; Dopants influence

\section{Introduction}

Low carbonized steel is a well-known Fe allow used as a material for various engineering details and constructions. Usually it contains up to 0.2 per cent of carbon and some small amounts of other dopants. There are some works where influence of dopants on the mechanical properties of steel is studied on the atomic level [1-5]. However, in the most of them only some energetic characteristics are studied, while engineers are interested in technical parameters. Here we present results of the tensile strength and the shift modulus calculations for the doped Fe.

\section{Methods and Models}

As real steel is a polycrystalline material consisted mainly of $\alpha$-Fe grains, its durability depends mainly on the durability of grain interfaces (borders). For this reason our investigation is limited with studying of the interface between two grains of $\alpha$-Fe.

It is well know that $\alpha$-Fe is a ferromagnetic with magnetic polarization of $2.2 \mu_{\mathrm{B}}$ per atom, $b c c$-lattice with period $a=2.867 \AA$, and cohesion energy of $5.48 \mathrm{eV}$. In this work we used the spin-polarized version of DFT realized within the FHI96md package [6] based ont he density functional theory (DFT) $[7,8]$ and the pseudo-potential method [9]. This package was previously used with advantage for many systems, including transition metal compositions [10-14]. In all cases, the generalized gradient approximation [15] to description of the exchange-correlation interactions has been chosen and the optimization of the atomic geometry has been performed. All pseudopotentials were constructed with the FHI98PP package [16]. They were checked for the absent of the so-called 'ghost' states and were used for founding the equilibrium lattice parameters, magnetic and the cohesion energy of $\alpha$-Fe.

To model the bulk $b c c \alpha$-Fe we used a cubic cell with two iron atoms: one atom was placed in the lattice cell corner; the second atom was situated in the center of the cell. The energy cut-off for the pane wave set was equal to 40 Ry and the special k-point $(0.25 ; 0.25 ; 0.25)$ was used. The self-consistence convergence was provided by stabilizing the total energy with an accuracy of $0.005 \mathrm{eV}$ per atom. We have found the equilibrium lattice constant of $2.88 \AA$, magnetic moment of 2.0 $\mu_{\mathrm{B}}$, and cohesion energy of $4.5 \mathrm{eV}$, in satisfactory accordance with experimental data.

An interface between two $\alpha$-Fe grains was modeled as a contact of two thin crystalline slabs having infinity dimensions in $\mathrm{X}$ and $Y$ directions. Thickness of the each slab was made of three atomic layers. The interacting slabs approached among themselves before the minimum of their total energy was achieved. The scheme of such system is given in Figure 1.

In order to test our approach we calculated the interface energy (the energy gain of iron grains bonding) and have obtained the value of $1.33 \mathrm{~J} / \mathrm{m}^{2}$. According to refs. [5,17] published values of the grain interface energy of Fe lie in the interval of $0.47-1.63 \mathrm{~J} / \mathrm{m}^{2}$.

After leading of the system in a state with the minimum energy we made computer experiments of two types (Figure 2). The top panel: investigation of the reaction of the interface to break; the down panel: investigation of the reaction of the interface to shift.

In the stretch case we found the variations of the total energy $\Delta \mathrm{E}$ as functions of elongation $\Delta \mathrm{Z}$, and then the applied strength $\mathrm{P}$ was

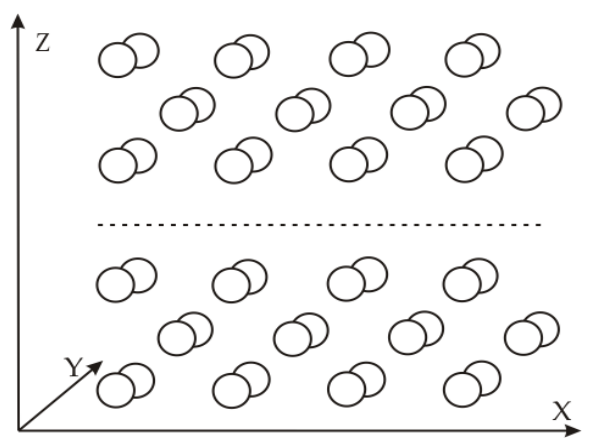

Figure 1: The scheme of the interface between two crystallites of alpha ferrite. The dotted line shows the defective plane in which there are no atoms inside of cubic cells.

*Corresponding author: Victor Zavodinsky, Institute for Materials Science of the Russian Academy of Sciences 153 Tikhookeanskaya str., Khabarovsk, 680042 Russia, Tel: 07(4212)226956; Fax: 07(4212)226598; E-mail: vzavod@mail.ru

Received June 24, 2017; Accepted July 11, 2017; Published July 21, 2017

Citation: Zavodinsky V, Kabaldin Y (2017) Influence of Dopants on Mechanica Properties of Steel: A Spin-Polarized Pseudopotential Study. J Material Sci Eng 6: 354. doi: 10.4172/2169-0022.1000354

Copyright: (c) 2017 Zavodinsky V, et al. This is an open-access article distributed under the terms of the Creative Commons Attribution License, which permits unrestricted use, distribution, and reproduction in any medium, provided the original author and source are credited. 
calculated according the formulae $P=\frac{\Delta E}{\Delta Z} \frac{1}{S_{X Y}}$, where $S_{\mathrm{XY}}$ is the system square in the XY plane. In the shift case we studied the dependence of $\Delta \mathrm{E}$ on $\operatorname{tg} \varphi$, where $\varphi$ is the shift angle, and calculated the shift module $\mathrm{G}: G=\frac{\Delta E}{\Delta X} \frac{1}{S_{X Y}} \frac{1}{\operatorname{tg} \phi}$.

\section{Results and Discussion}

\section{Undoped $\alpha$-Fe}

First of all we studied reaction of the undoped iron system on stretching along $\mathrm{Z}$ direction and on shift along $\mathrm{X}$ direction. Atoms of upper and down planes were moved step-by-step and fixed at the each step. Other atoms were able to relax up and to find equilibrium positions. The dependences of tension on elongation and energy on tangent of the shift angle are presented in Figure 3.

The top panel of this figure demonstrates the strength limit of 18 $\mathrm{GPa}$ for breaking the undoped $\alpha-\mathrm{Fe}$ grains interface. The down panel shows that the shift process has two stages. Firstly, the total energy grows sharply with the shift modulus of $160 \mathrm{GPa}$; secondly, the shift modulus decreased to $80 \mathrm{GPa}$. Comparatively, experimental value of

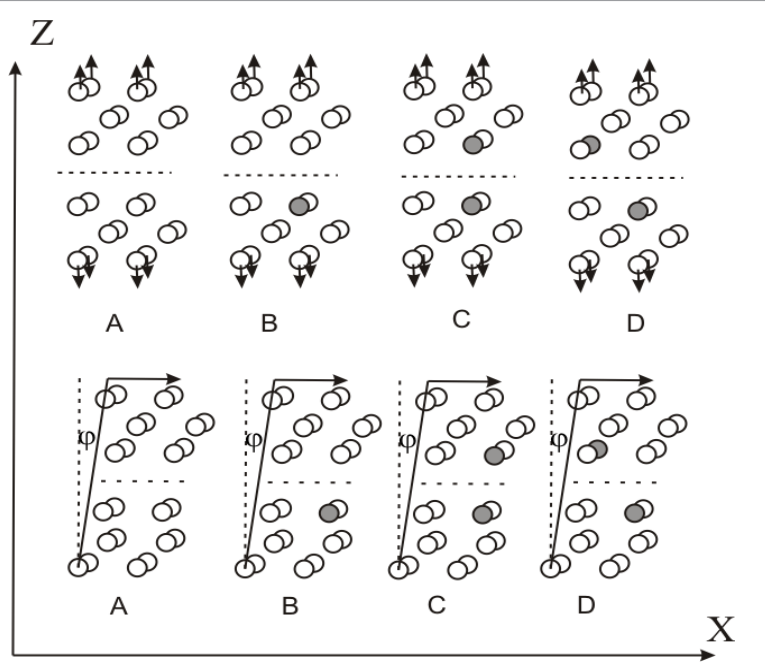

Figure 2: Schemes of computer experiments: A) undoped a-Fe grains interface; B) one dopant atom; C and D) two dopant atoms. Dopant atoms are shown as grey balls, $\varphi$ is a shift angle.

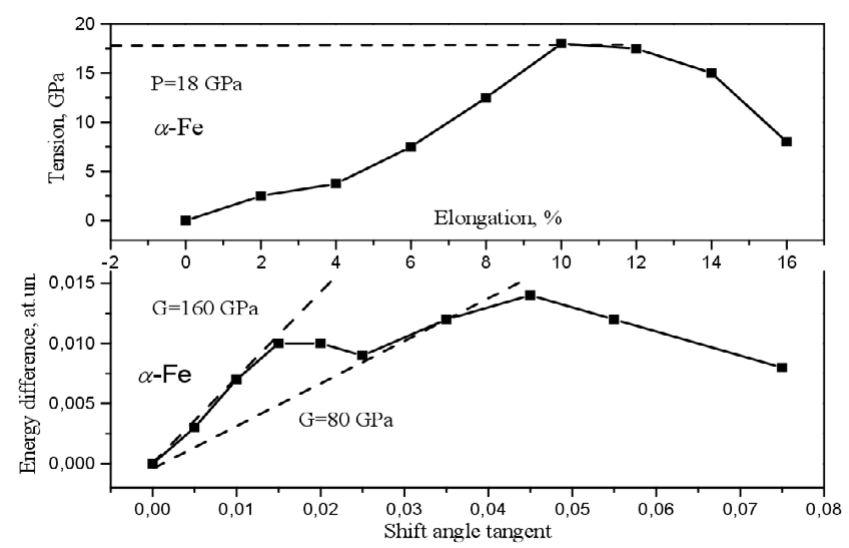

Figure 3: Stretch and shift study of the undoped $\alpha-F e$ grains interface. tensile strength is $60 \mathrm{MPa}$ for the low carbonized steel and $1.3 \mathrm{GPa}$ for single-crystalline whiskers. The published shift module value is 14 $\mathrm{GPa}[3]$.

\section{Dopants influence}

We placed dopant atoms as it is shown in Figure 2B-2D. Namely, for single-atomic cases we replaced one atom of the interface with $\mathrm{C}$, $\mathrm{P}, \mathrm{N}$ or $\mathrm{Ti}$ atom. For two-atomic cases (TiN or $\mathrm{TiC}$ ) dopant atoms were placed on both sides of the interface. Results of calculations are presented in Figure 4 and Table 1.

It is clear (Figure 4) that presence of carbon increases the tensile strength by 1.5 times in comparison with undoped ferrite; $\mathrm{N}$ and $\mathrm{Ti}+\mathrm{N}$ decrease it approximately by 20 percent. The $\mathrm{Ti}$ and $\mathrm{Ti}+\mathrm{C}$ cases demonstrate the tensile strength very close to the case of undoped iron. At another hand addition of carbon reduces the limit of elongation to 1 percent (for undoped $\alpha-\mathrm{Fe}$ it is 10 percent); nitrogen reduces it to 8 percent; while $\mathrm{Ti}, \mathrm{Ti}+\mathrm{N}$ and $\mathrm{Ti}+\mathrm{C}$ increase its value up to $14-18$ percent. As for phosphorus it decreases strongly both the tensile strength and the limit of elongation. In more details results are collected in Table 1.

Influence of dopants on the shift behavior of the Fe grains interface is much less significant than their effect for the stretch characteristics. Our modeling shows that in all doped cases the dependence of the shift module on the shift angle tangent looks like that of the undoped $\mathrm{Fe}$ case, and its value varies between 70 and $170 \mathrm{Gpa}$.

\section{Conclusion}

Quantum-mechanics modeling of the $\alpha$-Fe grains interface as a contact of two nano thin slabs lets us to obtain adequate data of dopants influence $(\mathrm{C}, \mathrm{P}, \mathrm{N}, \mathrm{Ti}, \mathrm{Ti}+\mathrm{C}$ and $\mathrm{Ti}+\mathrm{N})$ on mechanical properties of steel. Summarize all results we can conclude that addition of $\mathrm{Ti}$ (single or with $\mathrm{C}$ ) increases significantly the elongation limit keeping approximately the level of the tensile strength of un-doped iron. Thus, addition of $\mathrm{Ti}$ in the $\mathrm{C}$ doped $\alpha$-Fe can improve elasticity of steel details and constructions at low temperatures. Phosphorus is the worst impurity in steel.

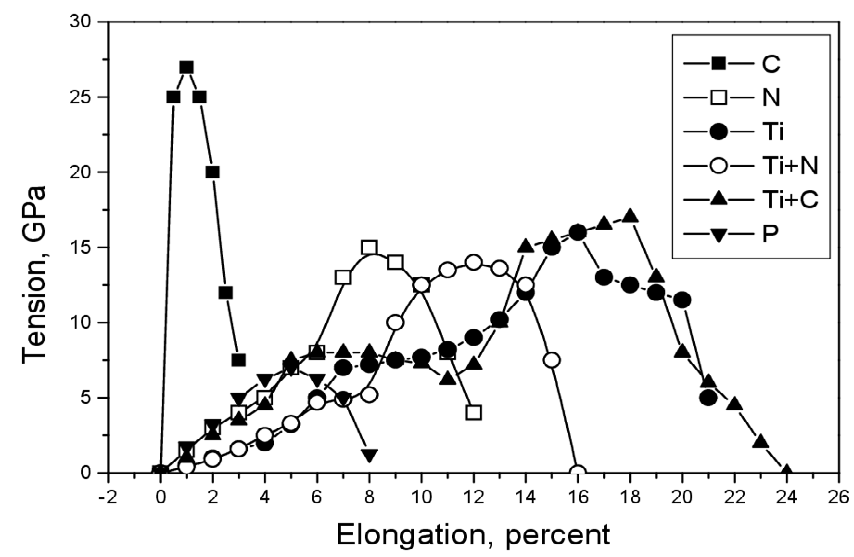

Figure 4: Stretch study of the dopant influence on durability of the Fe grains interface.

\begin{tabular}{|c|c|c|c|c|c|c|c|}
\hline System & Undoped $\mathbf{F e}$ & $\mathbf{F e}+\mathbf{C}$ & $\mathbf{F e}+\mathbf{N}$ & $\mathbf{F e}+\mathbf{T i}$ & $\mathbf{F e}+\mathbf{T i}+\mathbf{C}$ & $\mathbf{F e}+\mathbf{T i}+\mathbf{N}$ & $\mathbf{F e}+\mathbf{P}$ \\
\hline $\mathrm{P}, \mathrm{GPa}$ & 18 & 27 & 14.8 & 15.5 & 16.5 & 14.5 & 7.1 \\
\hline $\mathrm{L}$, percent & 10 & 1 & 8 & 16 & 18 & 12 & 5 \\
\hline
\end{tabular}

Table 1: Tensile strength $P$ and elongation limit $L$ for the Fe grains interface. 
Citation: Zavodinsky V, Kabaldin Y (2017) Influence of Dopants on Mechanical Properties of Steel: A Spin-Polarized Pseudopotential Study. J Material Sci Eng 6: 354. doi: 10.4172/2169-0022.1000354

Page 3 of 3

\section{References}

1. Kolesnikov V, Myasnikova N, Sidashov A, Myasnikov P, Kravchenko J, et al. (2010) Multilayered antifriction nanostraction covering for lubrication in the tribocoupling "wheel-rail”. Transport problems 5: 71-79.

2. Ridny YaM, Mirzoev AA, Mirzaev DA (2014) Ab initio modelirovanie azota $v$ GTsK-reshotke zheleza. Vestink Yuzhnogo Gosudarstvennogo Universiteta. Ser. Metallurgia (in Russian) 14: 59-63.

3. Hu SY, Ludwig M, Kizler P, Schmauder S (1998) Atomistic simulations of deformation and fracture of. Modelling and Simulation in Materials Science and Engineering 6: 567.

4. Oila A, Bull SJ (2009) Atomistic simulation of Fe-C austenite. Computational Materials Science 45: 235-239.

5. Verkhovykh AV, Mirzoev AA (2013) Ab intio modelirovanie energii formirovaniya granitsy zerna v OTsK-zheleze. Vestink Yuzhno-Uralskogo Gosudarstvennogo Universiteta. Ser. Metallurgia, Mekhanika, Fizika (in Russian) 5: 76-81.

6. Bockstedte M, Kley A, Neugebauer J, Scheffler M (1997) Density-functional theory calculations for poly-atomic systems: electronic structure, static and elastic properties and ab initio molecular dynamics. Computer physics communications 107: 187-222.

7. Hohenberg P, Kohn W (1964) Inhomogeneous electron gas. Physical Review 136: B864.

8. Kohn W, Sham LJ (1965) Self-consistent equations including exchange and correlation effects. Physical review 140: A1133.
9. Heine V, Weaire D (1970) Pseudopotential theory of cohesion and structure. Solid State Physics 24: 249-463.

10. Dabrowski J, Müssig HJ, Zavodinsky V, Baierle R, Caldas MJ (2002) Mechanism of dopant segregation to $\mathrm{SiO} 2 / \mathrm{Si}(001)$ interfaces. Physical Review B 65: 245305.

11. Zavodinsky VG (2004) The mechanism of ionic conductivity in stabilized cubic zirconia. Physics of the Solid State 46: 453-457.

12. Zavodinsky VG, Chibisov AN (2006) Zirconia nanoparticles and nanostructured systems. Journal of Physics: Conference Series 29: 173). IOP Publishing.

13. Zavodinsky VG (2010) Small tungsten carbide nanoparticles: Simulation of structure, energetics, and tensile strength. International Journal of Refractory Metals and Hard Materials 28: 446-450.

14. Zavodinsky VG (2011) Cobalt layers crystallized on the WC (100) surface: Spin-polarized ab initio study. International Journal of Refractory Metals and Hard Materials 29: 184-187.

15. Perdew JP, Burke K, Wang Y (1996) Generalized gradient approximation fo the exchange-correlation hole of a many-electron system. Physical Review B 54: 16533

16. Fuchs M, Scheffler M (1999) Ab initio pseudopotentials for electronic structure calculations of poly-atomic systems using density-functional theory. Computer Physics Communications 119: 67-98.

17. Chicago Zybin IN, Bulychev VV, Latypov RA (2015) Analiz energii granits zere $\mathrm{v}$ metallakh primenitelno $\mathrm{k}$ protsesu soedinenia metallov pri svarke davleniem. Sovremennye Problemy Nauki i Obrazovania 1: 18-23. 